\title{
Ultrasonic processing of aluminium alloys above the liquidus: the role of $\mathrm{Zr}$
}

\author{
Dmitry Eskin ${ }^{1,2 *}$ \\ ${ }^{1}$ Brunel Centre for Advanced Solidification Technology, Brunel University London, UB8 3PH Uxbridge, The United Kingdom \\ ${ }^{2}$ Tomsk State University, Tomsk 634050, Russian Federation
}

\begin{abstract}
Ultrasonic melt processing (USP) is gaining quite an interest in recent years due to the benefits of this technology to the melt quality and structure refinement. A number of mechanisms have been identified that govern the effects of USP at different stages of melt processing. Technologically it is advantageous to apply USP to the fluid melt rather than to a mushy solidifying alloy. In this case heterogeneous nucleation on available or activated/multiplied substrates is the main mechanism. Among these substrates, primary crystals of $\mathrm{Al}_{3} \mathrm{Zr}$ phase were shown to be potent and effective. This paper gives a review of the own research into the role of $\mathrm{Al}_{3} \mathrm{Zr}$ in structure refinement in various groups of $\mathrm{Al}$ alloys, from solid-solution type to hypereutectic. This overview includes the evidence of a possible eutectic reaction between Al and $\mathrm{Al}_{3} \mathrm{Zr}$ in Al-rich alloys, mechanisms of $\mathrm{Al}_{3} \mathrm{Zr}$ formation and refinement under USP (that enables these primary crystals to be active substrates for $\mathrm{Al}$ and some other primary phases), the role of USP in facilitating primary solidification of $\mathrm{Al}_{3} \mathrm{Zr}$ in the $\mathrm{Al}-\mathrm{Zr}$ system, and the additional benefits of solute $\mathrm{Ti}$ presence. The paper is illustrated with the data obtained over the last 15 years of research led by the author.
\end{abstract}

\section{Interaction of $\mathrm{Zr}$ with aluminium}

It seems like a strange topic to discuss as it is well known that the $\mathrm{Al}_{3} \mathrm{Zr}$ phase reacts with liquid aluminium through a peritectic reaction $\mathrm{L}+\mathrm{Al}_{3} \mathrm{Zr}$ $=(\mathrm{Al})$ at $661{ }^{\circ} \mathrm{C}(934 \mathrm{~K})$ [1] with the peritectic point at $0.28 \mathrm{wt}^{\mathrm{o}} \mathrm{Zr}$ and the maximum liquid solubility of $\mathrm{Zr}$ in (Al) $0.11 \mathrm{wt} \%$ at $661{ }^{\circ} \mathrm{C}$ [2]. This assumption works well for most practical purposes and seems to fit with most of experimental data. Nevertheless, some experimental observations, most notably the occurrence of small $\mathrm{Al}_{3} \mathrm{Zr}$ particles in the interdendritic spaces (i.e. grain/dendrite boundaries) after solidification, raise concerns about the solidification reaction in the Al-rich alloys with $\mathrm{Zr}$.

It is worth noting that most of the prior work on the equilibria in the Al corner of the Al- $\mathrm{Zr}$ phase diagram has been done by assessment rather than by direct measurements [1]. However, there were some obvious inconsistencies. McPherson and Hansen [3] reported a thermal arrest at $655^{\circ} \mathrm{C}$ for a sample containing 6.4 at.\% (18.7 wt\%) $\mathrm{Zr}$ though there had been no discussion of this particular measurement. More recently Janghorban et al. [4] performed careful thermal analysis involving pure Al reference samples and observed thermal arrests for a sample containing 1 at.\% (3.3 wt\%) $\mathrm{Zr}$ at 654 and $656{ }^{\circ} \mathrm{C}$, which indicated a eutectic reaction with the invariant temperature approximately $5{ }^{\circ} \mathrm{C}$ below the melting point of Al. They dismissed these results and ascribed them to errors in the measurement of the liquid compositions, i.e. the $\mathrm{Zr}$ content of the liquid in equilibrium with $\mathrm{Al}_{3} \mathrm{Zr}$.

Therefore, we performed a series of studies to clarify the phase equilibrium in the Al-Zr system by experiments and thermodynamic calculations [5, 6]. These studies have shown that, at least under certain, close to normal $(0.5$ to $5 \mathrm{~K} / \mathrm{s})$ casting conditions, the formation of fine $\mathrm{Al}_{3} \mathrm{Zr}$ particles at dendrite boundaries is a typical phenomenon in Al$\mathrm{Zr}$ alloys containing 0.15 to $1 \mathrm{wt} \% \mathrm{Zr}$ (Fig. 1). $\mathrm{Zr}$ should, of course, segregate to the centre of a grain if it follows a peritectic solidification reaction. Its segregation to the grain boundaries may be a good indicator of a eutectic solidification. The nature of the particles as $\mathrm{Al}_{3} \mathrm{Zr}$ has been established using transmission and scanning electron microscopy and energy dispersive X-ray analysis [5, 6]. Accurate differential thermal analysis of as-cast samples identified a temperature arrest at $659{ }^{\circ} \mathrm{C}$ [5]. More refined DTA analyses on samples annealed for long times showed the thermal arrest to be close to 659.9 ${ }^{\circ} \mathrm{C}$ [6]. The discrepancy between these results may be due to lack of equilibration of the as-cast samples. This correlates well with the thermodynamically predicted decrease of the invariant reaction temperature using the results of $a b$ initio and CALPHAD calculations ( 0.1 to $0.2 \mathrm{~K})$ 
[6]. The experimentally determined temperature is lower than the melting point of pure aluminium, which confirms the presence of a eutectic reaction that may look like shown in Fig. 2. Note that the eutectic point in the new version almost coincides with the peritectic point (maximum liquid solubility) in the currently adopted version of the $\mathrm{Al}-\mathrm{Zr}$ phase diagram. The question whether this eutectic solidification reaction is equilibrium or nonequilibrium remains open.

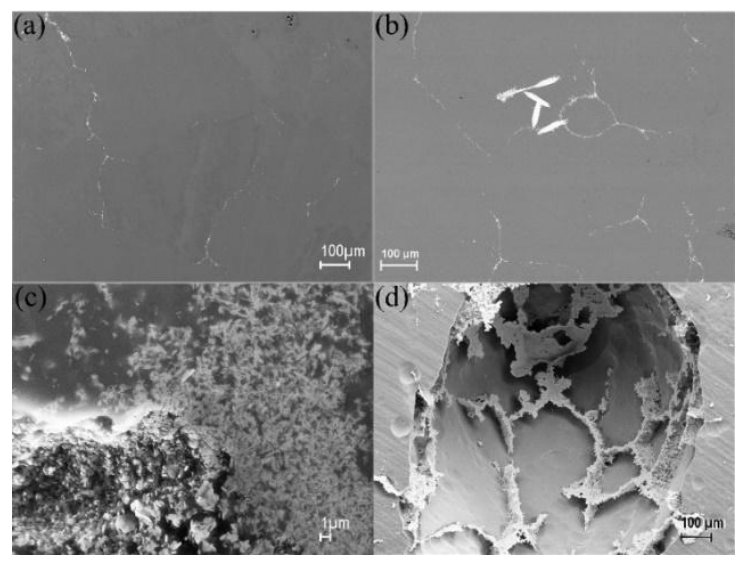

Fig 1. Secondary electron images of grainboundary particles formed during solidification in an $\mathrm{Al}-0.4 \mathrm{wt} \% \mathrm{Zr}$ alloy at cooling rates of $5 \mathrm{~K} / \mathrm{s}$ (a) and $1 \mathrm{~K} / \mathrm{s}(\mathrm{b}-\mathrm{d})$ : $\mathrm{a}, \mathrm{b}$, general view; c, higher magnification of grain boundary particles; and $\mathrm{d}$, deep etching of the matrix [5].

It is well known that the formation of $\mathrm{Al}_{3} \mathrm{Zr}$ primary phase is rather sluggish, which is a reason of $\mathrm{Zr}$ supersaturating the aluminium solid solution during solidification. As the alloys with Sc (eutectic phase diagram) prove, it is not the consequence of the type of the phase diagram but rather the kinetics effect of the primary phase formation. Therefore, the suggested change of the

\section{Effects of $\mathrm{Zr}$ in grain refinement of aluminium alloys}

Zirconium is added to aluminium alloys for several purposes: to prevent or control recrystallization [7], to enhance mechanical properties and thermal stability while retaining electrical conductivity [8], and to control grain size during solidification [9]. In the first two cases, supersaturation of the Al solid solution is achieved during solidification and the metastable $\mathrm{L}_{2} \mathrm{Al}_{3} \mathrm{Zr}$ phase precipitates during annealing, pinning dislocations and subgrain boundaries [7]. In the last case, primary crystals of the equilibrium $\mathrm{Al}_{3} \mathrm{Zr}$ phase act as nucleating substrates for $\mathrm{Al}$ grains [10]. Non-equilibrium accelerated solidification of Al-rich Al-Zr alloys typically results in either formation of a solidification reaction does not change the fact that the $\mathrm{Al}-\mathrm{Zr}$ alloys are forming supersaturated solid solution during solidification, albeit the amount of $\mathrm{Zr}$ available for that will be the function of how much $\mathrm{Zr}$ has been consumed by primary and, now, eutectic particles.

In addition to the contribution to the general knowledge on the $\mathrm{Al}-\mathrm{Zr}$ solidification sequence, the revealed eutectic nature of the $\mathrm{Al}-\mathrm{Zr}$ phase diagram has implications for the applications that are related to the formation of the primary $\mathrm{Al}_{3} \mathrm{Zr}$ phase, e.g. grain refinement that will be considered later in the paper. As only primary particles are useful for the grain refinement, the occurrence of the eutectic reaction renders part of $\mathrm{Zr}$ introduced into the alloy useless. Therefore, we need to look at the conditions when the primary solidification is promoted while eutectic reaction is suppressed.

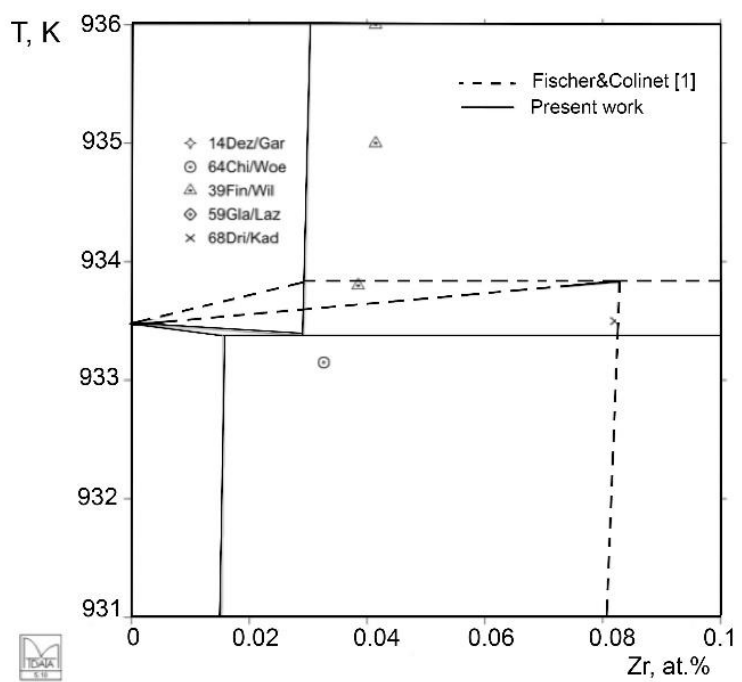

Fig 2. Comparison of the reference phase diagram for $\mathrm{Al}$ rich corner of the $\mathrm{Al}-\mathrm{Zr}$ system with the new version of the phase diagram based on ab initio and CALPHAD results [6].

supersaturated solid solution of $\mathrm{Zr}$ in $\mathrm{Al}$ or the formation of the metastable $\mathrm{Al}_{3} \mathrm{Zr}$ phase [11]. So the solidification conditions that promote the formation of the primary particles need to be met to achieve the desired grain refining effect.

Primary $\mathrm{Al}_{3} \mathrm{Zr}$ particles should, however, be of rather small size to realize the potential of a grain refiner. Ultrasonic cavitation has long been known to be an efficient means of primary crystal refinement, and also the role of primary $\mathrm{Al}_{3} \mathrm{Zr}$ particles in grain refinement upon ultrasonic processing (USP) has been reported already in the 1960s [12]. Later on, the important role of $\mathrm{Zr}$ in the improved efficiency of USP for grain refinement of 
a range of aluminium alloys has been demonstrated on laboratory and industrial scale [13, 14, 15, 16].

In the studies reported here we used a $5-\mathrm{kW}$ water-cooled magnetostrictive transducer coupled with a $\mathrm{Nb}$ sonotrode $(17.5 \mathrm{kHz}$, amplitude at least $\pm 20 \mathrm{~m})$. The alloys were prepared in an electric furnace and the USP has been done in the temperature range above the formation of primary (Al) grains.

Ultrasonic melt processing facilitates the refinement of primary aluminides, including $\mathrm{Al}_{3} \mathrm{Zr}$, through enhanced nucleation on oxides and through fragmentation [17]. To achieve the best results, the processing should be applied above the liquidus of (Al) but within the temperature range of primary solidification of $\mathrm{Al}_{3} \mathrm{Zr}[15,17]$. The refined to a size of a few $m$ primary aluminides act as a very efficient substrate for (Al) grains. Figure 3 illustrates this for a number of alloying systems and a range of casting processes. One can see that the significant grain refinement can be achieved not only in hypoeutectic alloys (Fig. 3a-f), but also in such heterogeneous alloys as hypereutectic $\mathrm{Al}-\mathrm{Ni}$ and $\mathrm{Al}-\mathrm{Fe}$ (where eutectic grains become refined, Fig. 3i, j)) [16]. Small additions of Ti facilitate the grain refining effect of $\mathrm{Al}_{3} \mathrm{Zr}$ upon USP as has been studied in detail elsewhere [15] and thought to be due to the growth restriction effect of solute $\mathrm{Ti}$ and a possible change in the surface energy of $\mathrm{Al}_{3} \mathrm{Zr}$ doped with Ti [9]. As a result of these studies, an $\mathrm{Al}-\mathrm{Zr}-\mathrm{Ti}$ master alloy has been suggested as a specialised grain refiner for aluminium alloys cast with USP [18] (Fig. 3g, h).

It has been shown that USP of the melt above and through the primary solidification range of $\mathrm{Al}_{3} \mathrm{Zr}$ promotes its nucleation and refinement as illustrated in Fig. 4a, b [9, 15, 17]. The number of primary particles increase dramatically after USP while their size decreases. One can notice that the morphology of the particles also changed from a flat dendrite to a plate, which should be more favourable for acting as a nucleating substrate. What is more striking is that the amount of $\mathrm{Al}_{3} \mathrm{Zr}$ particles at the dendrite boundaries decreased significantly, which is further illustrated in Fig. 4c, d.

The enhanced nucleation of primary $\mathrm{Al}_{3} \mathrm{Zr}$ particles upon USP leaves less free $\mathrm{Zr}$ in the system to react by the eutectic reaction, effectively suppressing it. The potential of $\mathrm{Al}_{3} \mathrm{Zr}$ (refined during USP) becomes available for grain refinement.

A small addition of $\mathrm{Ti}$ seems to assist in promoting the primary phase formation at the expense of the "eutectic" one. Figure $4 \mathrm{e}$ shows that there are more primary $\mathrm{Al}_{3} \mathrm{Zr}$ particles in the presence of Ti with somewhat decreased amount of grain-boundary crystals. The primary particles are then refined upon USP with virtually no grainboundary particles formed as shown in Fig. 4f.
These observations suggest one more mechanism of positive effect of $\mathrm{Ti}$ on grain refinement induced by primary $\mathrm{Al}_{3} \mathrm{Zr}$, i.e. suppressing eutectic reaction in the $\mathrm{Al}-\mathrm{Zr}$ system and promoting formation of primary crystals. There may be three reasons for that: (a) shifting the equilibrium towards the peritectic solidification and/or (b) changing the thermodynamic properties of the $\mathrm{Al}_{3} \mathrm{Zr}$ phase to facilitate its formation; and/or (c) changing the activity of oxides that act as substrates for $\mathrm{Al}_{3} \mathrm{Zr}$, e.g. via increased wettability.

\section{Conclusions}

1. The interaction between $\mathrm{Al}$ and $\mathrm{Zr}$ may be more complicated than it is accepted. An equilibrium or nonequlibriun (preudo) eutectic reaction may take place in Al-rich alloys under conventional casting conditions. This results in the formation of $\mathrm{Al}_{3} \mathrm{Zr}$ particles at the dendrite boundaries, effectively decreasing the amount of primary $\mathrm{Al}_{3} \mathrm{Zr}$ phase.

2. Ultrasonic melt processing performed above the liquidus of $(\mathrm{Al})$ but in the range of primary formation of $\mathrm{Al}_{3} \mathrm{Zr}$ results in significant refinement of primary $\mathrm{Al}_{3} \mathrm{Zr}$ particles through enhanced nucleation on oxides and fragmentation. An additional effect of USP is in the decreased amount of $\mathrm{Al}_{3} \mathrm{Zr}$ particles formed at the dendrite boundaries.

3. Small additions of $\mathrm{Ti}$ seem to suppress the eutectic reaction and promote primary solidification of $\mathrm{Al}_{3} \mathrm{Zr}$. The mechanism of this is still unclear and may be related to the shift in thermodynamic equilibrium or changed surface energy of the phases involved.

4. The enhanced grain refinement of a wide range of $\mathrm{Al}$ alloys by USP in the presence of $\mathrm{Zr}$ and $\mathrm{Ti}$ is due to the favourable combination of factors, i.e. suppression of eutectic reaction, promotion of primary $\mathrm{Al}_{3} \mathrm{Zr}$ formation and refinement of its particles through enhanced heterogeneous nucleation and fragmentation.

\section{Acknowledgements}

This overview paper is a summation of efforts of many researchers with whom I collaborated over many years. I would like to acknowledge the contribution of $\mathrm{T}$. Atamanenko, L. Zhang, F. Wang, T. Subroto, G. Salloum-Abou-Jaoude, S. Chankitmunkong, A. Khvan, C. Fang, and A. Dinsdale. Also the financial support of M2i (The Netherlands) for projects MC4.05215 and M11.5.11419 and EPSRC (The United Kingdom) for projects Ultra-Cast (Grant EP/L019884/1) and UltraMelt2 (Grant EP/R011095/1) is highly appreciated. 

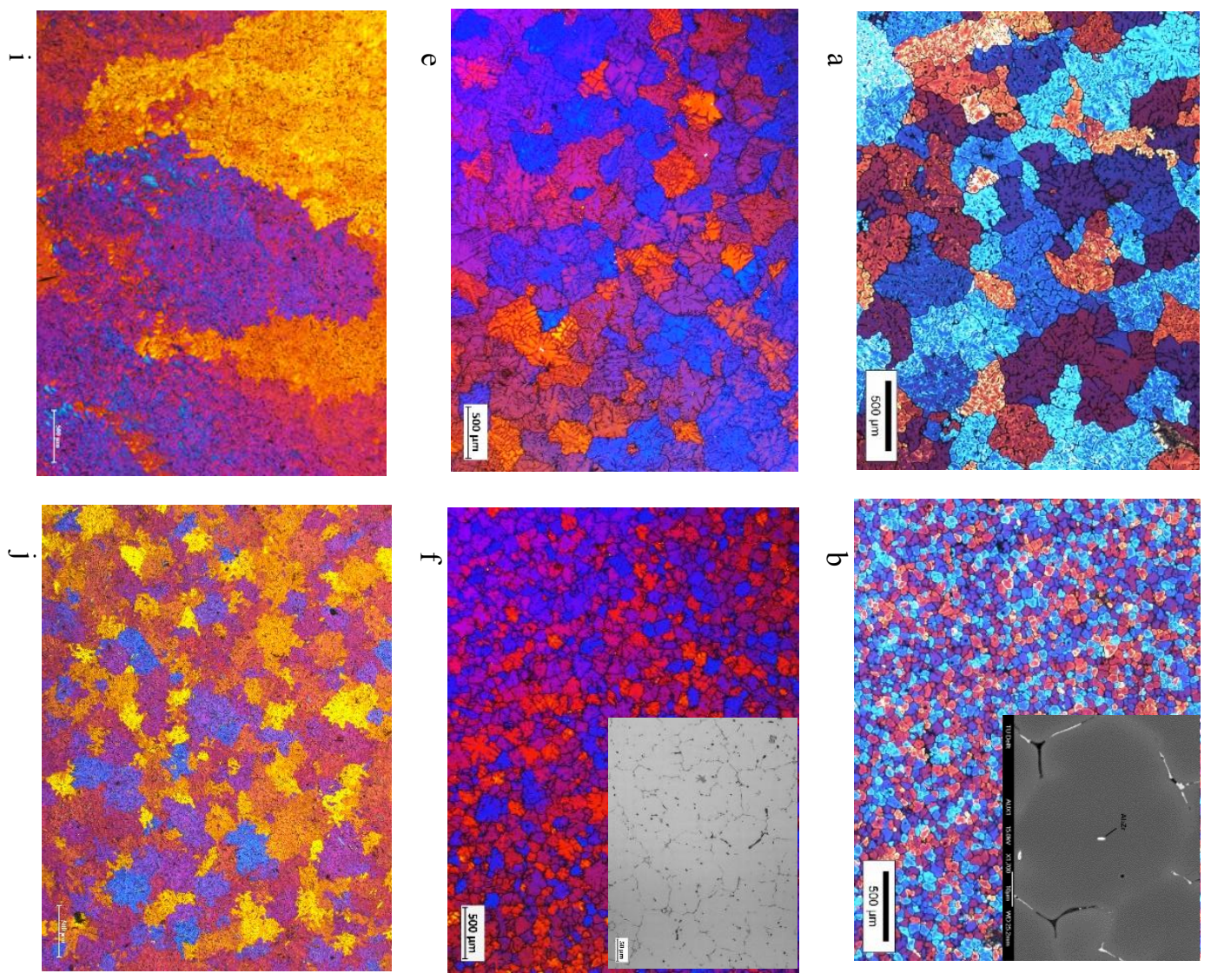

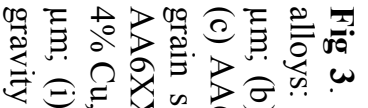

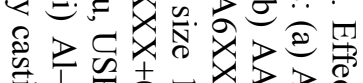

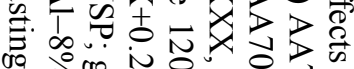
Z Z Z :

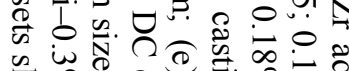

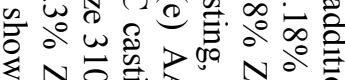

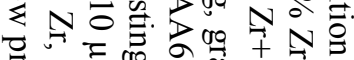

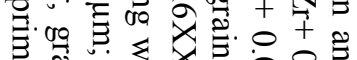

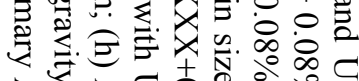
$\gtrless \geq \cong$ o N

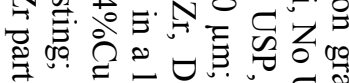

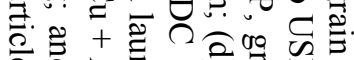

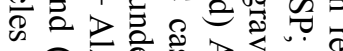

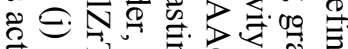

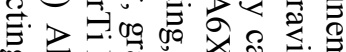
क \&

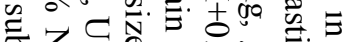
Zn

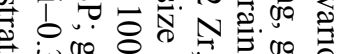

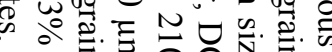

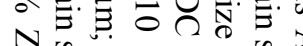

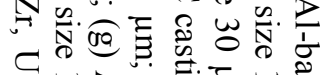

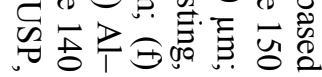
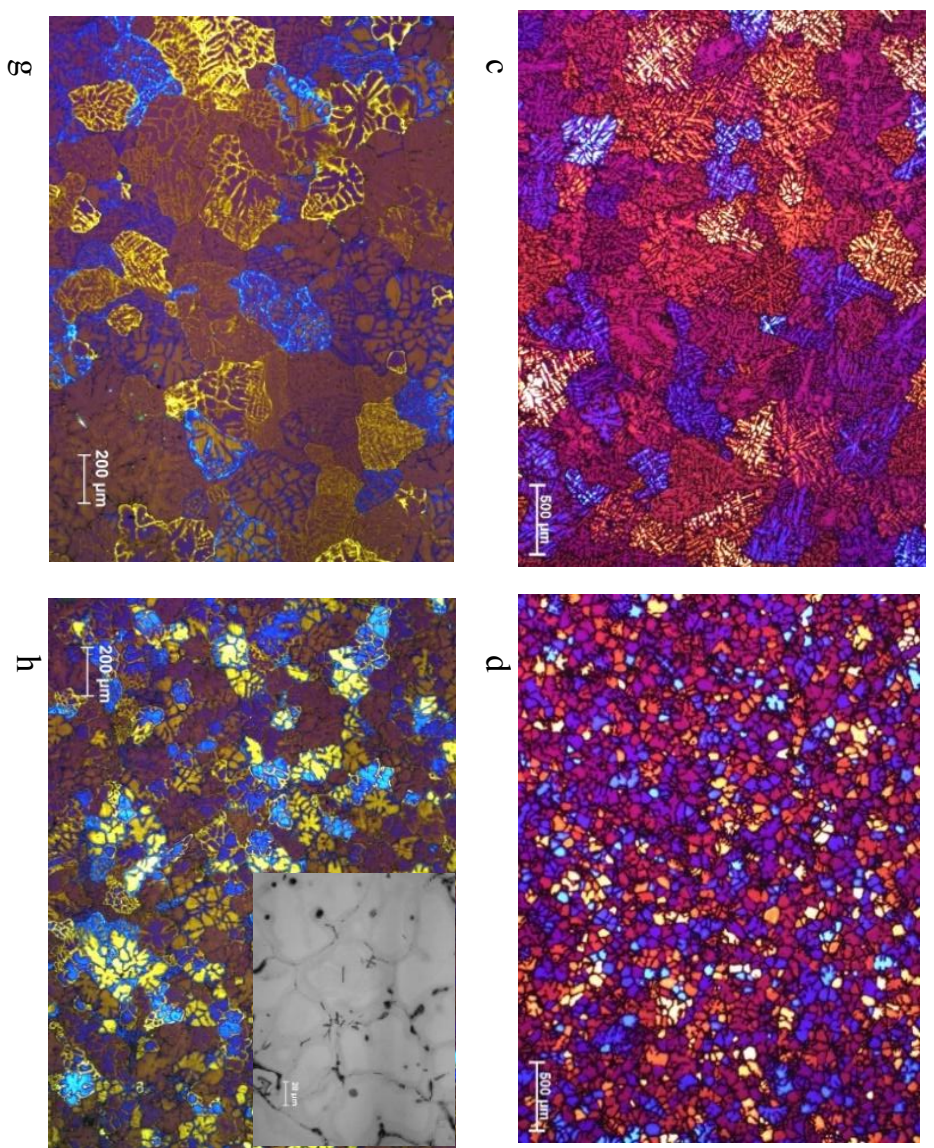


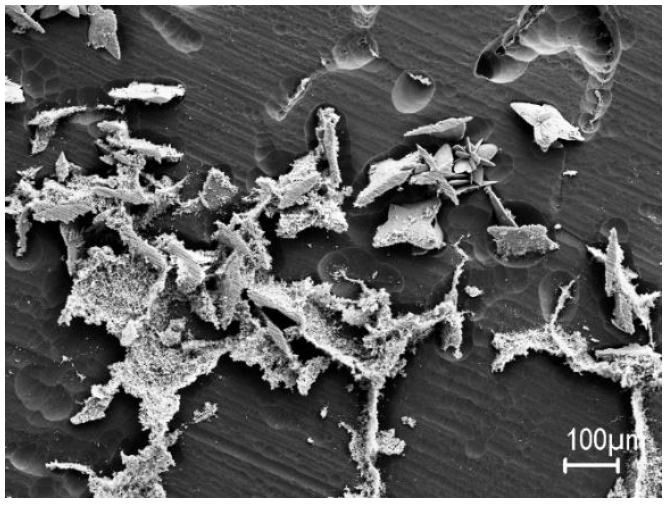

a

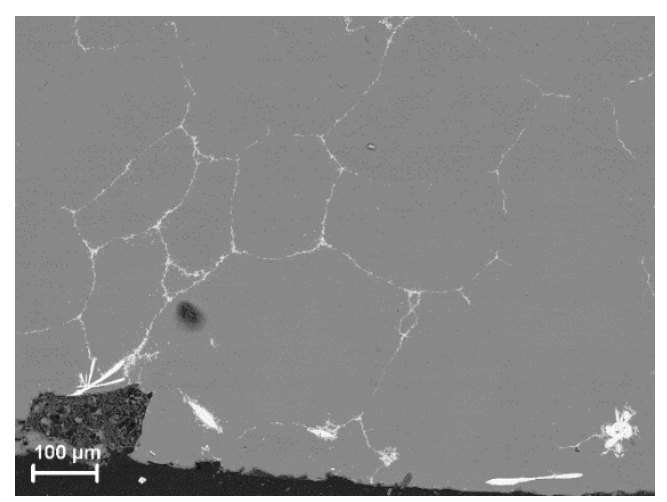

c

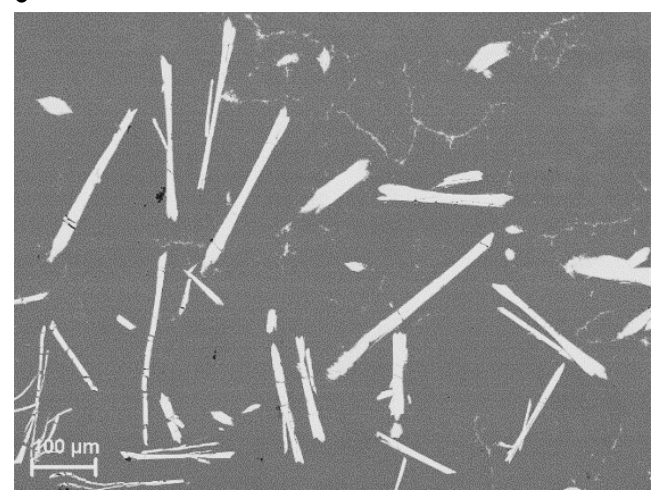

e

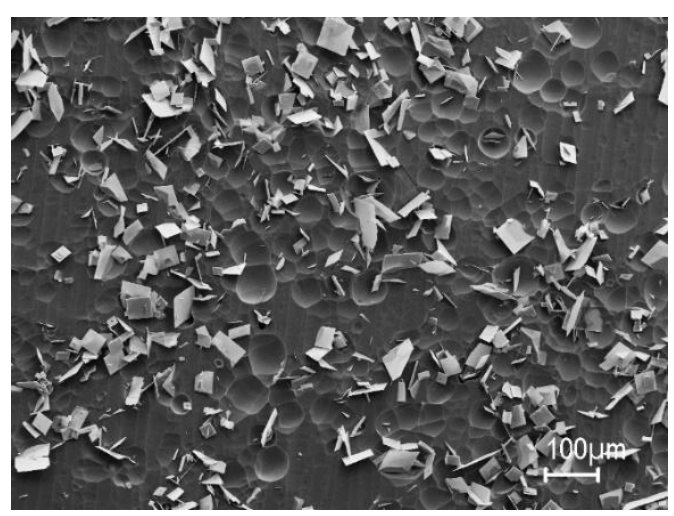

b
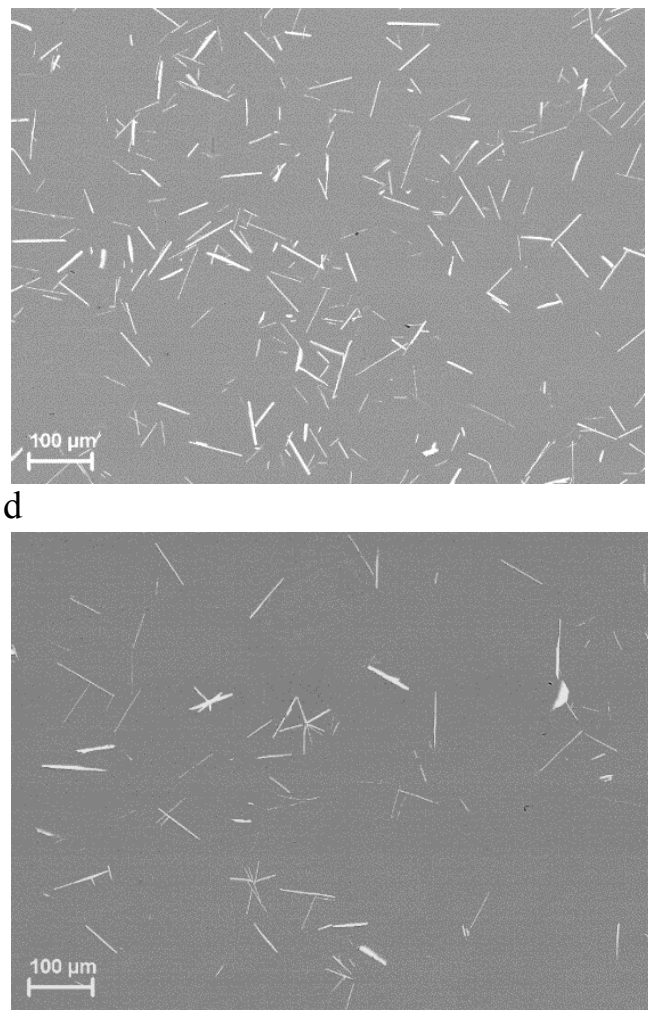

f

Fig 4. Effect of USP and Ti addition on the formation of $\mathrm{Al}_{3} \mathrm{Zr}$ phase during solidification: (a) $\mathrm{Al}-0.4 \% \mathrm{Zr}$, deep etched (note primary $\mathrm{Al}_{3} \mathrm{Zr}$ flat dendrites and fine grain-boundary crystals); (b) $\mathrm{Al}-0.4 \% \mathrm{Zr} \mathrm{Ti}$, USP (note plateshaped primary $\mathrm{Al}_{3} \mathrm{Zr}$ ); (c) $\mathrm{Al}-0.4 \% \mathrm{Zr}$; (d) $\mathrm{Al}-0.4 \% \mathrm{Zr}$, USP; (e) $\mathrm{Al}-0.4 \% \mathrm{Zr}-0.1 \% \mathrm{Ti}$; and (f) $\mathrm{Al}-0.4 \% \mathrm{Zr}-$ $0.1 \% \mathrm{Ti}$, USP.

\section{References}

[1] E. Fischer, C. Colinet, J. Phase Equilbr. Diff. 36 (2015) 404-413.

[2] L.F. Mondolfo, Aluminum Alloys: Structure and Properties, Butterworths, 1976.

[3] D. J. McPherson, M. Hansen, Trans. ASM 46 (1954) 354-74.

[4] A. Janghorban, A. Antoni-Zdziobek, M. LomelloTafin, C. Antion, Th. Mazingue, A. Pisch, J. Therm. Analysis Calorim. 114(3) (2013) 1015-1020

[5] F. Wang, D.G. Eskin, A.V. Khvan, K.F. Starodub, J.J.H. Lim, M.G. Burke, T. Connolley, J. Mi. Scr. Mater. 133 (2017) 75-78.
[6] A.V. Khvan, D.G. Eskin, K.F. Starodub, A.T.

Dinsdale, F. Wang, C. Fang, V.V. Cheverikin, M.V. Gorshenkov, J. Alloys Comp. 743 (2018) 626-638.

[7] N. Ryum, Acta Metall. 17 (1969) 269-278.

[8] N.A. Belov, A.N. Alabin, I.A. Matveeva, D.G. Eskin, Trans. Nonferr. Met. Soc. China 25 (2015) 2817-2826.

[9] T.V. Atamanenko, D.G. Eskin, M. Sluiter, L. Katgerman, J. Alloys Comp. 509 (2011) 57-60.

[10] F. Wang, D. Qiu, Z.-L. Liu, J.A. Taylor, M.A. Easton, M.-X. Zhang, Acta Mater. 61 (2013) 5636-5645. [11] E. Nes, H. Billdal, Acta Metall. 25 (1977) 10311037.

\footnotetext{
*Corresponding author: dmitry.eskin@brunel.ac.uk
} 
[12] G.I. Eskin. Ultrasonic processing of molten aluminium ( Metallurgiya, Moscow, 1965).

[13] G.I. Eskin. Ultrasonic treatment of light alloy melts, $1^{\text {st }}$ Edn. (Gordon and Breach, Amsterdam, 1998).

[14] G.I. Eskin, D.G. Eskin. Ultrasonic treatment of light alloy melts, $2^{\text {nd }}$ Edn. ( CRC Press, Boca Raton, 2015).

[15] T.V. Atamanenko, D.G. Eskin, L. Zhang, L.

Katgerman. Metall. Mater. Trans. A 41A (2010) 20562066.

[16] S. Chankitmunkong, D.G. Eskin, C. Limmaneevichitr. Mater. Sci. Eng. A. 2020 (submitted) [17] F. Wang, D. Eskin, T. Connolley, J. Mi. Trans. Nonferr. Met. Soc. China 27 (2017) 977-985.

[18] V.M. Sreekumar, D.G. Eskin. JOM 68 (2016) 30883093. 